\title{
Larval Host Preference and Suitability for the Sawfly Mesoneura rufonota among Five Cinnamomun Tree Species
}

\author{
Jiaying Zhou ${ }^{1}$, Jiangtao Zhang ${ }^{1}$, Tom Tregenza ${ }^{2}{ }^{\circledR}$, Youliang Pan ${ }^{1}$, Qinzhao Wang ${ }^{1}$, Haoni Shi ${ }^{1}$ \\ and Xingping Liu ${ }^{1, *}$ \\ 1 Key Laboratory of State Forestry and Grassland Administration on Forest Ecosystem Protection and \\ Restoration in Poyang Lake Watershed, College of Forestry, Jiangxi Agriculture University, \\ Nanchang 330045, China; jyzhou1106@outlook.com (J.Z.); jiang_tao_zhang@163.com (J.Z.); \\ pan1649034597@163.com (Y.P.); qinzhaowang@163.com (Q.W.); shn1029384756@163.com (H.S.) \\ 2 Centre for Ecology \& Conservation, School of Biosciences, University of Exeter, Penryn Campus, Falmouth, \\ Cornwall TR10 9FE, UK; T.Tregenza@exeter.ac.uk \\ * Correspondence: xpliu@jxau.edu.cn; Tel.: +86-791-83813243
}

Received: 25 December 2019; Accepted: 16 January 2020; Published: 22 January 2020

\begin{abstract}
The camphor sawfly, Mesoneura rufonota Rohwer, is an economically important leaf-chewing pest of the genus Cinnamomum Trew. However, little is known about the range of species that it can infest within this genus or whether larvae show preferences for particular species. We conducted preference and performance experiments under laboratory conditions to assess larval host preference and suitability as a host plant of five congeneric trees species: C. camphora (Linn) Presl, C. bodinieri Levl., C. burmanni (Nees et T. Nees) Blume, C. pauciflorum Nees, and C. micranthum (Hay.) Hay. In no-choice, two-choice and multiple-choice feeding trials, significantly higher feeding rates were found on C. camphora, followed by C. bodinieri, compared to those on the other three tree species. In two-choice behavior trials, larvae moved to occupy leaves of $C$. camphora faster and more frequently, followed by $C$. bodinieri, than when offered the other three tree species. In no-choice fitness trials, the survival of larval and pupal stage was the highest, the developmental duration of larval and pupal stage was the shortest, the pupal body weight was the heaviest and adults lived the longest on C. camphora followed by C. bodinieri, while M. rufonota did not complete development on C. burmanni, C. pauciflorum or C. micranthum. Our results demonstrate that larvae consistently prefer and perform better on C. camphora leaves, that they can utilize C. bodinieri, but it is less preferred, and that C. burmanni, C. pauciflorum, and C. micranthum appear to be unsuitable as a host for M. rufonota.
\end{abstract}

Keywords: Mesoneura rufonota; host suitability; host preference; performance; Cinnamomum

\section{Introduction}

Insects constitute the most diverse group of animals on Earth, and a large fraction of insect species are phytophagous [1]. Exploring the relationship between phytophagous insects and host plants has been a central topic for many evolutionary ecologists, biologists, and pest control experts [2-4]. Host plant range is a key ecological characteristic for phytophagous species as it defines their resource base, which in turn is an important factor influencing their population dynamics and interactions with other phytophagous species, predators, and parasites [5]. Thus, it is of great significance in evolutionary ecology theory and pest control practice to investigate the host plant range of phytophagous insects. In nature, phytophagous insects differ in their degree of specialization on host plants, and range from strictly monophagous species to extremely polyphagous species [6-8]. For oligophagous and polyphagous insects, the selection of a suitable host plant is essential to ensure their development 
and reproduction [3,9], and having a large host plant range is considered to be an evolutionary advantage [10]. A broad host range may allow oligophagous species to colonize new hosts in areas where their original or preferred hosts are absent or much less abundant [11]. Understanding the process of host plant selection by phytophagous insects and their impact on various life-history traits has been a major goal of insect evolutionary ecology [12,13]. In recent decades, the behavioral mechanisms by which phytophagous insects locate and select potential host plants have been extensively documented [14,15]. However, the vast majority of this work has focused on host plant selection of phytophagous insects for feeding or egg-laying by adult insects [3,7,16-18], while the role of larval stages in host plant selection has received less attention in empirical studies to date [19-22].

The genus Cinnamomum Trew belonging to the family Lauraceae comprises about 250 species which are distributed in China, India, Sri-lanka, and Australia [23]. Forty-six species are native to China and some of them are widely cultivated in southern China as shade trees because they are fragrant evergreen broad-leaved species, such as Cinnamomum camphora (Linn) Presl, C. bodinieri Levl., and C. micranthum (Hay.) Hay etc. They are also economically important for medicine, pesticides, natural flavors, and fragrances [24]. However, in recent years, a large number of pests in these trees have occurred with the gradual enlargement of the cultivation area. The camphor sawfly, Mesoneura rufonota Rohwer (Hymenoptera: Tenthredinidae), is an economically important leaf-chewing insect pest, native to China and first reported in the 1960s on camphor tree C. camphora [25]. Previous studies of the biological characteristics indicated that this pest can complete one to seven generations per year in different regions in China and overwinters as mature larvae (prepupae) within cocoons in the soil [26-28]. Adults usually leave their pupation cells in mid to late March. Newly emerged adults exhibit stronger flight ability. Females lay eggs on the tender leaves of host plants, beginning shortly after leaving their pupal chambers. The larvae then feed gregariously on the tender leaves, causing large economic losses and ecological effects [26]. The larvae are considered to be oligophagous. Their reported host plants focus on the genus Cinnamomum and the primary host is C. camphora [25,26]. Larvae often move frequently to forage host plants under field conditions, especially in the case of lacking food. Situations where two host plants of different species are in contact with one another such that larvae may need to choose between the two species, will not be very common in nature but they will occasionally occur. Some interesting questions arise from here. Are there alternative host plants that might allow populations that would otherwise be inviable to survive in areas where the primary host is less common? Could alternative hosts allow M. rufonota to spread across areas where the primary host is absent? Alternatively, are there other plant species that sawfly larvae will attempt to feed on, but where they cannot complete development? Such species could potentially be useful in control strategies.

Considering the potential for this pest to cause heavy damage and the economic importance of the genus Cinnamomum, there is a critical need for broader and more precise information on host preference and suitability of this pest. This information is indispensable to better understand the potential effect of the camphor sawfly on different host species. However, currently, there is no information available in the literature on the host preference of this pest among different species of the genus Cinnamomum. To our knowledge, no attempt has been made to investigate the life history traits of M. rufonota on the different species of the genus Cinnamomum in China. Therefore, we sought to determine the larval preference and performance for five congeneric tree species of the genus Cinnamomum commonly present in China.

Our first objective was to compare the leaf-feeding preference and rate of larvae among five different plant species using no-choice, two-choice, and multiple-choice feeding trials. Our second objective was to assess the extent to which larvae would choose to move towards and begin feeding on plants of different species through two-choice trials. Our third objective was to determine the impact on several life-history parameters of this insect of different potential host plants. The results of our study will throw light on the potential host plant range of this sawfly with potential applications for integrated pest management. 


\section{Materials and Methods}

\subsection{Plant Materials}

To represent a range of the most common potential host species, we collected five congeneric tree species in the genus Cinnamomum which are widely cultivated in the landscape in China as a subset of the potential host plants to use in this study: C. camphora (Linn) Presl (CCP), C. bodinieri Levl. (CBL), C. micranthum (Hay.) Hay (CMH), C. burmanni (Nees et T. Nees) Blume (CBB), and C. pauciflorum Nees (CPN). These trees were cultivated in the nursery garden of Jiangxi Agricultural University. Freshly tender leaves were collected from different individuals of each species and used for the following experiments.

\subsection{Insects Rearing}

All M. rufonota larvae used in the experiments were obtained from the second generation of a colony originally derived from natural populations of multiple broods in Jinxi County, Jiangxi Province, China $\left(28^{\circ} 2^{\prime} 33^{\prime \prime} \mathrm{N}, 116^{\circ} 44^{\prime} 39^{\prime \prime}\right.$ E) in March 2019. Third to fourth instar larvae were collected from the tender leaves of C. campora and brought into the forest protection laboratory of Jiangxi Agricultural University. The wild-collected larvae were placed in transparent plastic boxes (length $\times$ width $\times$ height $=20 \times 15 \times 7 \mathrm{~cm}$ ) and maintained in artificial climate incubators at a constant temperature of $25 \pm 1{ }^{\circ} \mathrm{C}$ and $70 \pm 10 \%$ relative humidity with $14 \mathrm{~h}$ light: $10 \mathrm{~h}$ dark regime. To reduce maternal effects and to expose the larvae to all the new hosts before the commencement of the experiments, we reared larvae with freshly collected tender leaves from a mixture of all five potential host plants simultaneously. Host plants were provided in excess and replaced daily until the pre-pupal stage was attained. Upon maturation, we allowed larvae to pupate and placed pupae into empty wooden mesh cages (length $\times$ width $\times$ height $=30 \times 30 \times 40 \mathrm{~cm}$ ). Newly emerged adults were transferred into new cages and permitted to mate freely. They were provided with a fresh branch of camphor tree as mating and oviposition site. Newly laid eggs were collected daily and transferred into transparent plastic boxes lined with moistened filter paper and placed in incubators under the same conditions. Standard camphor sawfly rearing techniques were used throughout the study [28]. Newly hatched larvae were used in the larval performance experiment or were colony reared using the same method described above until their third instar. Then the third-instar larvae were used in larval preference experiments. We conducted all of these experiments at $25 \pm 1{ }^{\circ} \mathrm{C}$ and $70 \pm 10 \%$ relative humidity with $14 \mathrm{~h}$ light: $10 \mathrm{~h}$ dark regime in artificial climate incubators (larval performance experiments) and air-conditioned chamber (larval preference experiments). These conditions represent a subset of the conditions that host and insects experience in the field.

\subsection{Larval Preference Experiments}

\subsubsection{Larval Feeding Rate across Host Plants}

To examine larval feeding rates on different host species, we performed no-choice, two-choice and multiple-choice leaf-feeding trials simultaneously. Leaf squares (length $\times$ width $=2 \times 2 \mathrm{~cm}$ ) were cut from the freshly harvested tender leaves of each of the five plant species before the experiments were conducted. In no-choice feeding trials, a leaf square of one of the five potential host plants was placed in the center of a small plastic petri dish $(\mathrm{d}=8.5 \mathrm{~cm}, \mathrm{~h}=1.5 \mathrm{~cm})$ lined with moist filter paper. In two-choice feeding trials, two leaf squares of two different plant species were placed in a similar petri dish. In multiple-choice feeding trials, leaf squares from each of the 5 plants species were arranged at random, avoiding overlapping, in a large plastic petri dish $(\mathrm{d}=20 \mathrm{~cm}, \mathrm{~h}=2.5 \mathrm{~cm})$. A single third-instar larva that had been kept isolated from food for the previous $3 \mathrm{~h}$ was transferred into the dish. All of the petri dishes were sealed with thin transparent plastic wrap to prevent larva escape. After $24 \mathrm{~h}$, traces of larval feeding were observed and area (\%) of the leaf square eaten was calculated. Leaf area consumed was measured by placing the consumed leaf squares on top of 1-mm-grid graph paper. 
The leaf was carefully outlined with a pencil on the graph paper. The total number of grid squares within the outline of the leaf was counted. The leaf squares with the largest and smallest area eaten represented the most and least preferred plants for larval feeding, respectively. Each possible host plant or combination of host plants was replicated thirty times in each design.

\subsubsection{Larval Choice Behavior across Host Plants}

To compare the attractiveness of different host plants, two-choice behavior trials were performed using leaf squares. We placed two freshly cut $4 \mathrm{~cm}^{2}$ leaf squares derived from different plant species in a small plastic petri dish lined with moist filter paper. A single third-instar larva that had been food-deprived for the previous $3 \mathrm{~h}$ was transferred into the center of the petri dish. We observed the dish continuously and counted the larvae on each particular tested leaf square, and recorded the time between introduction and the first observation of feeding. Observations were continued for $1 \mathrm{~h}$. Thirty replicates of each of the 10 possible pairwise combinations of five host plants were performed. Larvae that did not feed at any point during the observation were discarded from the analysis.

\subsection{Larval Performance Experiments}

To determine whether plant species affect larval performance, we compared life-history parameters among newly hatched larvae reared on each of the five potential host plants. We performed 10 replicates of our life-history study for each tree species. Within each replicate, we selected thirty newly hatched larvae randomly and transferred them into a transparent rectangular plastic box (length $\times$ width $\times$ height $=20 \times 15 \times 7 \mathrm{~cm}$ ) lined with moist filter paper and containing excess freshly harvested tender leaves from one of the five host plants. We replaced the filter paper and food daily and monitored larvae until pupation. We recorded the developmental duration of the larval stage, the number of larvae surviving to pupation and the weight of the pupa. We harvested and placed cocoons into a small transparent plastic cylinder $(\mathrm{d}=5 \mathrm{~cm}, \mathrm{~h}=10 \mathrm{~cm})$ using soft forceps. When adults emerged from their cocoons, we recorded the developmental duration of the pupal stage and counted the number of adults as measures of the survival rates of the pupal stage. On emergence, sawflies were sexed and placed individually in small transparent plastic cylinders. We recorded adult lifespan in the absence of host species.

\subsection{Statistical Analysis}

All data analyses were carried out with SPSS version 19.0 for Windows (SPSS Inc., Chicago, IL, USA). The proportion data were arcsine square-root transformed prior to analysis. Then the data were first checked for homogeneity of variance and normality using frequency histograms and the Shapiro-Wilks test. Non-parametric tests were performed in cases where variances were heteroscedastic and/or distributions were not normal. We performed Kruskal-Wallis tests in no-choice trials and in multiple-choice trials, and independent sample Mann-Whitney U-tests in two-choice trials to explore the effects of tree species on larval feeding rate and the time taken to move to the leaf. We performed a binomial test to compare the difference in terms of the numbers of larvae approaching each species in two-choice trials. Life history parameters were analyzed using one-way ANOVA. Although survival itself is a dichotomous trait, the distribution of the proportion of individuals surviving within each host plant was better suited to a normal distribution according to our experiment design. The least significant difference (LSD) method was used for comparison of means. Data are expressed as median and interquartile $25-75 \%$ range in the larval preference experiment and are presented as means \pm SE in the larval performance experiment. 


\section{Results}

\subsection{Larval Feeding Rate across Host Plants}

All of the five tested tree species were eaten by M. rufonota larvae to some extent, although the extent of their utilization as a host plant varied substantially. When larvae were restricted to feeding on one of the tree species in no-choice trials, larvae fed on significantly larger portions of CCP and CBL than on the other tree species with the feeding rate of $75 \%$ and $34 \%$, respectively. The feeding rate per larva varied significantly among tree species tested (Kruskal-Wallis test: $H=102.97, d f=4$, $p<0.001$; Figure 1a). However, no significant difference was found in the feeding rate when larvae were restricted to feeding on $\mathrm{CMH}, \mathrm{CPN}$, and CBB $(p>0.05)$. When given a choice of all five tree leaves together in multiple-choice trials, a similar trend was observed with lower feeding rates on CBL than CCP and very low incidence of feeding on CMH, CPN, and CBB (Kruskal-Wallis test: $H=35.99, d f=4$, $p<0.001$; Figure 1b). In addition, when given a choice between pairs of tree species in two-choice trials, larvae significantly favored CCP, followed by CBL, with CBB, CPN, and CMH in low-ranking positions (Mann-Whitney U-test, $p<0.001$ ), except for in the pairwise combination of CPN and CBB (Mann-Whitney U-test, $W=368, p=0.22$, Table 1).
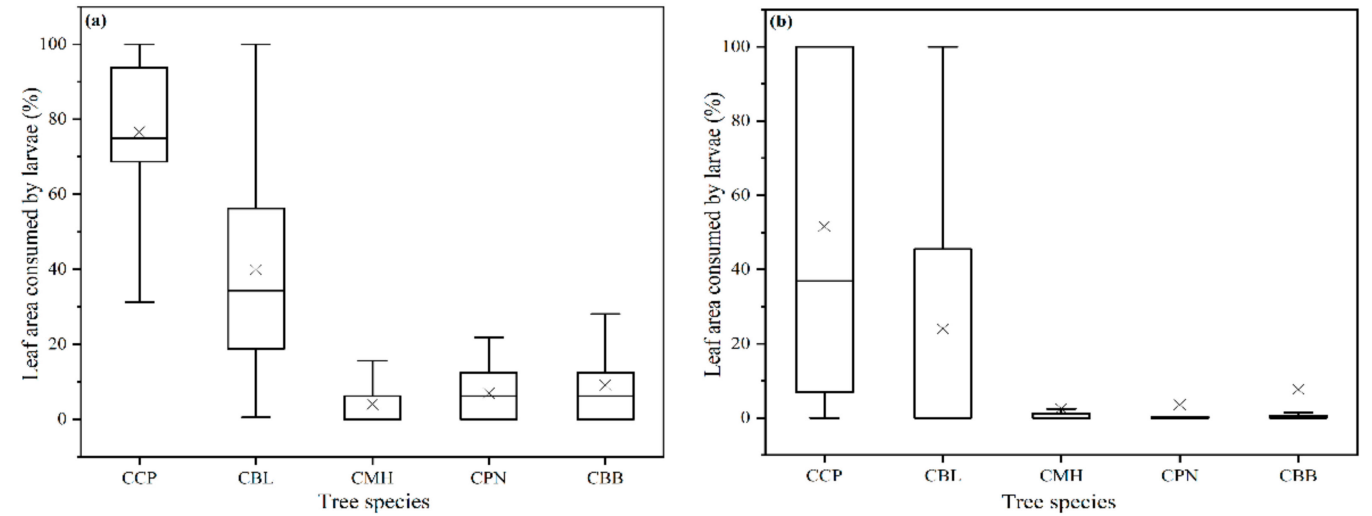

Figure 1. Median percentage (with interquartile $25-75 \%$ range in parentheses) of leaf area consumed by Mesoneura rufonota larvae under (a) no-choice trials and (b) multiple-choice trials. (CCP: C. camphora (Linn) Presl, CBL: C. bodinieri Levl., CMH: C. micranthum (Hay.) Hay, CBB: C. burmanni (Nees et T. Nees) Blume, CPN: C. pauciflorum Nees). The line and crosses inside the boxes indicate the medians and means, respectively; the heights of the boxes indicate the first and third quartiles, and the whiskers indicate the data range.

Table 1. Median percentage (with interquartile $25-75 \%$ range in parentheses) of leaf squares $\left(\mathrm{cm}^{2}\right)$ consumed by Mesoneura rufonota larvae under 10 pairwise combinations in two-choice trial.

\begin{tabular}{|c|c|c|c|c|c|}
\hline \multicolumn{2}{|c|}{ Tree Species } & $\mathrm{CCP}$ & CBL & $\mathrm{CMH}$ & CPN \\
\hline CBL & $\begin{array}{c}\text { Percentage } \\
W\end{array}$ & $\begin{array}{c}97.9(71.8,100) ; \\
63.9(30.1,76.1) \\
61.0^{* *}\end{array}$ & & & \\
\hline $\mathrm{CMH}$ & $\begin{array}{c}\text { Percentage } \\
W\end{array}$ & $\begin{array}{c}100(100,100) \\
0(0,0.3) \\
0^{* *}\end{array}$ & $\begin{array}{c}91.5(78.1,95.6) \\
0(0,0.1) \\
9.5^{* *}\end{array}$ & & \\
\hline CPN & $\begin{array}{c}\text { Percentage } \\
W\end{array}$ & $\begin{array}{c}100(100,100) ; \\
2.8(1.1,3.8) \\
27.5^{* *}\end{array}$ & $\begin{array}{c}82.5(72.5,90) \\
6.3(0,25) \\
14\end{array}$ & $\begin{array}{c}0(0,0) ; \\
1.8(1.2,4.2) \\
63^{* *}\end{array}$ & \\
\hline CBB & $\begin{array}{c}\text { Percentage } \\
\text { W }\end{array}$ & $\begin{array}{c}98.8(93.6,100) \\
0.5(0,1.5) \\
41.0^{* *}\end{array}$ & $\begin{array}{c}50(27.6,71.8) \\
0(0,2.8) \\
46.5^{* *}\end{array}$ & $\begin{array}{c}0(0,0) ; \\
0.1(0,0.8) \\
92.5^{*}\end{array}$ & $\begin{array}{c}0.8(0.4,1.3) \\
0.6(0,1) \\
368 \mathrm{~ns}\end{array}$ \\
\hline
\end{tabular}




\subsection{Larval Choice Behavior across Host Plants}

Although there were some larvae that did not approach a leaf, apart from the combinations CCP vs. CBL or CPN, third-instar larvae did move to occupy a leaf from one of the species offered in the two-choice leaf square trials. Significantly more larvae moved to CCP than CBL, and relatively few larvae were found on $\mathrm{CMH}$ than on the other tree species in its pairwise combinations (Binominal test, $p<0.05$, Figure 2). The time it took larvae to crawl to the different tree species was assessed among ten possible plant combinations. When CCP was combined with other tree species, larvae found their way to CCP significantly faster than to the other tree species (Mann-Whitney U-tests: CCP vs. CBL: $W=35.5, p=0.012$; CCP vs. CPN: $W=23.5, p=0.027$; CCP vs. CBB: $W=25.5, p=0.015 ; \mathrm{CPP}$ vs. CMH: $W=1, p=0.011$; Figure 3). CBL was also more attractive to larvae than CBB, CPN, and CMH (Mann-Whitney U-tests: CBL vs. CPN: $W=10.50, p=0.015$; CBL vs. CBB: $W=24.5, p=0.028$; CBL vs. $\mathrm{CMH}: W=3, p=0.037$; Figure 3). However, no statistical difference was evident across CBB, CPN, and $\mathrm{CMH}$ leaves in their pairwise combinations (Mann-Whitney U-test: $p>0.05$, Figure 3).

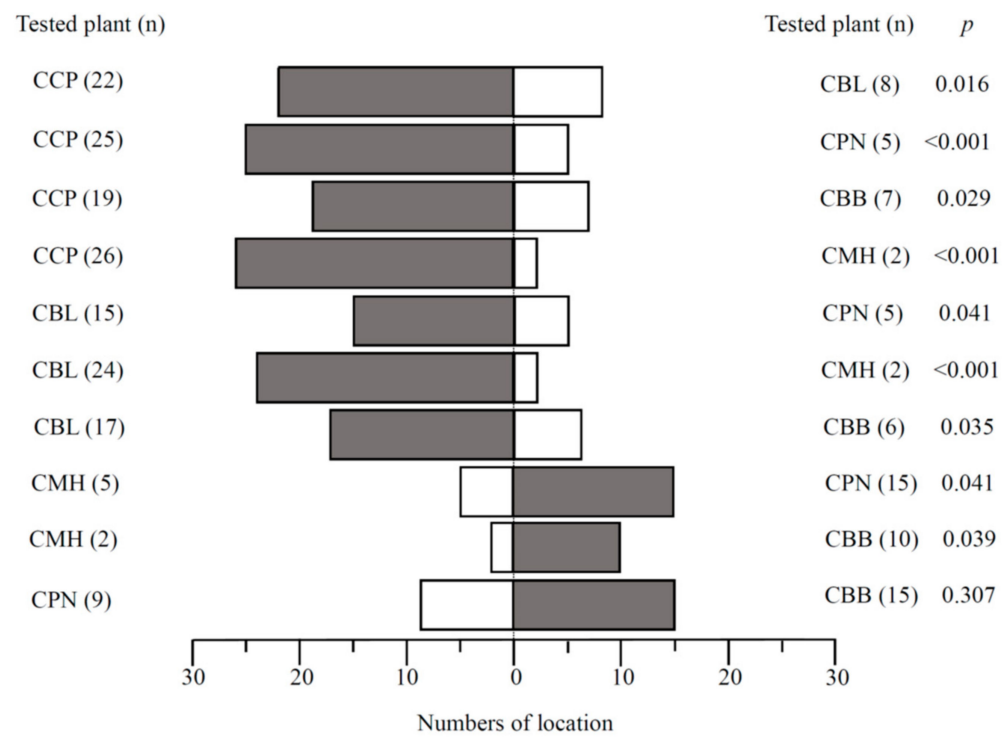

Figure 2. Numbers of Mesoneura rufonota larvae on leaves of each tree species in 10 pairwise combinations in two-choice trials.

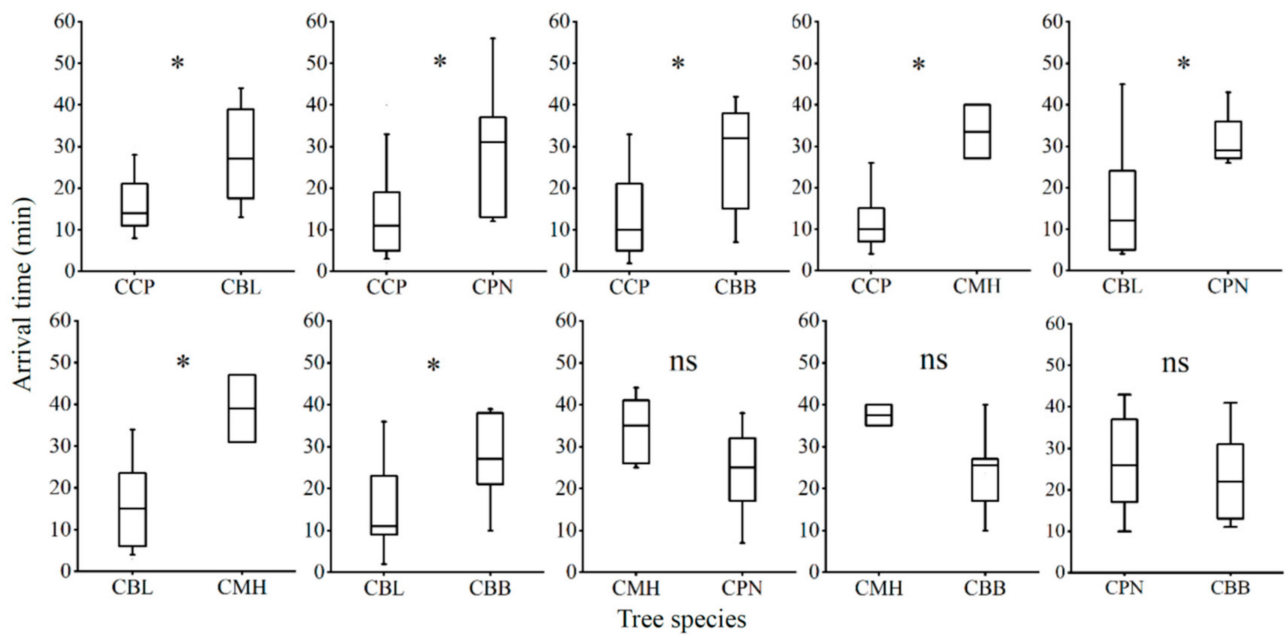

Figure 3. Time it took Mesoneura rufonota larvae to move to a leaf square of each tree species in 10 pairwise combinations in two-choice trials $(* 0.01<p<0.05, \mathrm{~ns}=\operatorname{not}$ significant $(p>0.05))$. 


\subsection{Larval Performance across Host Plants}

Host plant-related life-history traits of M. rufonota are presented in Table 2 . There was an $84 \%$ survival rate for larvae reared on $\mathrm{CCP}$, followed by $45 \%$ for $\mathrm{CBL}$, whereas less than $10 \%$ of larvae reared on $\mathrm{CMH}$, $\mathrm{CPN}$, and $\mathrm{CBB}$ survived. The differences were significant (ANOVA, $F=249.24, d f=4,45, p<0.0001$ ). The duration of larval development was the shortest on CCP and longest on $\mathrm{CMH}$. There were significant differences in larval developmental durations among the five tree species $(F=4.47, d f=4,466, p=0.001)$. The food consumed by M. rufonota during its larval stage significantly affected pupal weight, with heavier pupal weight on CCP than on other tree species $(F=9.16, d f=4,129, p<0.0001)$. No adults eclosed from CMH, CPN, and CBB food treatments. Significantly higher pupal survival, shorter developmental duration in pupal stages, and longer adult lifespan was observed in the CCP treatment compared to the CBL treatment (pupal survival: $F=341.25$, $d f=4,45, p<0.0001$; pupal developmental duration: $F=19.74$, $d f=1,295, p<0.0001$; adult lifespan: $F=11.47, d f=1,295, p=0.001)$.

Table 2. Mean ( \pm SE) of life-history parameters of Mesoneura rufonota when reared on leaves from the five different tree species in the laboratory.

\begin{tabular}{cccccc}
\hline Tree Species & CCP & CBL & CMH & CPN & CBB \\
\hline Larval survival (\%) & $84.33 \pm 2.98 \mathrm{a}$ & $45.00 \pm 2.59 \mathrm{~b}$ & $3.67 \pm 1.16 \mathrm{c}$ & $10.33 \pm 1.82 \mathrm{c}$ & $10.67 \pm 1.71 \mathrm{c}$ \\
Pupal survival (\%) & $88.88 \pm 3.03 \mathrm{a}$ & $54.11 \pm 3.94 \mathrm{~b}$ & $0 \mathrm{c}$ & $0 \mathrm{c}$ & $0 \mathrm{c}$ \\
Larval developmental & $8.60 \pm 0.06 \mathrm{~b}$ & $8.86 \pm 0.08 \mathrm{~b}$ & $9.27 \pm 0.30 \mathrm{a}$ & $9.00 \pm 0.15 \mathrm{ab}$ & $8.97 \pm 0.12 \mathrm{ab}$ \\
duration (d) & & & - & - \\
$\begin{array}{c}\text { Pupal developmental } \\
\text { duration (d) }\end{array}$ & $7.25 \pm 0.05 \mathrm{~b}$ & $7.73 \pm 0.12 \mathrm{a}$ & - & $0.19 \pm 0.01 \mathrm{~b}$ & $0.19 \pm 0.01 \mathrm{~b}$ \\
Pupal weight (g) & $0.23 \pm 0.01 \mathrm{a}$ & $0.20 \pm 0.01 \mathrm{~b}$ & $0.16 \pm 0.01 \mathrm{c}$ & - & - \\
Adult lifespan (d) & $4.01 \pm 0.05 \mathrm{a}$ & $3.64 \pm 0.10 \mathrm{~b}$ & - & \\
\hline
\end{tabular}

Means followed by the same letter within the same row are not significantly different (ANOVA, LSD test, $p>0.05$ ).

\section{Discussion}

Three important findings arise from our study. First, M. rufonota larvae exhibited significant host preferences among the five congeneric tree species we provided. Larvae preferred C. camphora, followed by C. bodinieri, to C. burmanni, C. pauciflorum, and C. micranthum. Second, more M. rufonota larvae moved towards and onto C. camphora leaf squares and they did so more rapidly than on the other tree species. Finally, M. rufonota larvae had dramatically higher performance in terms of development and survival of immature stages, pupal weight, and adult lifespan when reared on C. camphora, and did not complete development on C. burmanni, C. pauciflorum, and C. micranthum as manifested by higher larval and pupal mortality. Assuming that shorter development times, higher survival, and higher final mass are advantageous (as seems likely), these results demonstrate that C. camphora is the most preferred and suitable host for M. rufonota larvae. C. bodinieri is a potentially suitable host and C. burmanni, C. pauciflorum, and C. micranthum appear to be unsuitable as a host for M. rufonota.

The frequency and suitability of host plant species encountered by phytophagous insects can vary in time and space because of heterogeneity in the environment, disturbance, colonization, and intra- or interspecific interactions [29]. For herbivorous insects, ecological theory and empirical data on host plant selection provide evidence that adults can engage in host-plant selection for their offspring by choosing to lay their eggs on particular plants $[3,7,13,17,18,29-31]$, However, there is now accumulating evidence revealing that immature life stages can also play an active role in host discrimination, especially in Lepidopterans [19-22,32,33]. We find evidence of M. rufonota larval preference for C. camphora and $C$. bodinieri as measured by the mass of leaf consumed by the larvae and by the larval choice of host plants and time spent on each leaf. Our findings provide a new example regarding interactions between host selection behaviors and plant preferences of an oligophagous Hymenopteran.

When leaf squares were presented individually or in multiples, we found examples of larvae feeding on all of the species we tested (Figure 1). This was expected since the threat of starvation will drive many insects to exhibit wider polyphagy when they only have access to less-suitable host plants [34]. Similar 
behavior has been observed in other insects, such as Trichoplusia ni [32]. However, when M. rufonota larvae were offered pairwise combinations of host plants, they showed a clear preference for C. camphora, followed by C. bodinieri, with C. burmanni, C. pauciflorum, and C. micranthum in low-ranking positions, indicating that M. rufonota larvae have evolved the capacity to detect and favor their main natural host plants (Table 1, Figures 2 and 3). The mechanisms underlying potential host selection by M. rufonota larvae are still uncertain. The superficial similarity of the leaves of the five species, particularly once they are cut into square pieces makes visual discrimination unlikely. It is likely that olfactory signals originating from host plants are used by larvae as reported in a number of phytophagous insects [12,35,36], providing evidence that olfaction can mediate orientation in immature stages [20].

Numerous studies have reported that the biological and life history parameters of many insects, such as development, survival, body weight and reproductive rate, differ significantly among host species [37-39] or cultivars [40]. These effects on life history are important determinants of plant suitability for phytophagous insects. Shorter development times, higher survival, and higher rates of reproduction of insects on a host indicate greater suitability [41,42]. Our results demonstrate a positive correlation between larval preference and their performance on the plants that we provided to them. Larvae in non-choice performance assays were more likely to complete their development on the species that were most preferred in our preference assays.

Developmental duration is potentially an important component of fitness, as it determines how long different pre-reproductive stages are exposed to hazards including predators and parasites [38]. Our no-choice fitness trials show that the developmental duration of larval and pupal stages of camphor sawfly was remarkably shorter on C. camphora than on other host species (Table 2). The shorter developmental duration may provide an important selective advantage under pressure from natural enemies, as demonstrated by several authors [41]. Thus, a reduction in developmental duration on $C$. camphora could represent an advantage to $M$. rufonota by reducing its vulnerability to parasitism and predation. Similar results have been reported in other insect species, such as Plutella xylostella [42]. Although development was relatively poor on $C$. bodinieri, it also supported the development and population establishment of M. rufonota.

Our results revealed distinct differences in survival of $M$. rufonota immature stages, with the sawfly failing to complete development on C. burmanni, C. pauciflorum, and C. micranthum. Therefore, we expect these tree species will have lower infestations in the field due to their lower suitability. Previous field studies have suggested that C. camphora is the plant most heavily infested by M. rufonota [26,28]. Our results concur with these findings as well as providing evidence that $C$. bodinieri is a potentially suitable host for the survival of M. rufonota. M. rufonota performed the worst on C. burmanni, C. pauciflorum, and C. micranthum as manifested by higher larval and pupal mortality (Table 2). Numerous studies in phytophagous insects have demonstrated that larger pupal size is beneficial for subsequent reproduction, showing the positive relationship between pupal mass and adult fecundity [41]. Heavier pupal weight was found in C. camphora reared larvae in our experiment, further showing C. camphora is the dominant host plant for M. rufonota. In many Hymenopteran, adults utilize nutrients derived from larval reserves for maintenance as they do not feed [43]. Thus, adult lifespan is dependent entirely on resources acquired during larval development [44]. Our results show that the adult lifespan was significantly longer on C. camphora than on C. bodinieri (Table 2), also suggesting C. camphora is a more suitable host to C. bodinieri for M. rufonota.

We did not specifically control the diet of the mothers of insects used in our study so theoretically, non-genetic maternal effects could have influenced the host plant preference of the individuals we studied. There is very limited evidence for strong maternal effects on host plant preferences in insects so we regard this as unlikely to be a part of the explanation for our results. A related issue is that although we provided larvae pre-feeding-trials with a mixture of food plants, they are likely to have eaten more of some species than other species. If larvae have some retained preference for host plants that they have fed on previously, this could affect their subsequent preferences. Investigating this would need further experiments. 
In general, our findings reveal differences in the performance of lab-reared M. rufonota larvae on five potential host trees. Of the five host species tested, C. camphora exhibited high-quality host, followed by C. bodinieri, and C. burmanni, C. pauciflorum, and C. micranthum being consistently the least suitable host. There are three probable reasons to explain these results. First, some constituent compounds, especially nutrients, acquired from the host plants the individuals feed on can greatly impact the performance and fitness of individuals [45]. Second, plant primary and secondary metabolites or toxic compounds may have a strong influence on the performance of phytophagous insects [39,46-48]. Finally, physiological barriers inherent in these host plant species may affect feeding, and consequently, led to differences in the development and survival of insects [49]. Concerning M. rufonota larvae, secondary plant substances or physiological barriers seem to be the factors that play a decisive role in its feeding and growth, as closely related plant species may be expected to yield similar nutritional value to feeding herbivore [39]. However, the exact cause of the differences found among host plants in larval host preferences and performance remains unknown and, therefore, additional research is needed to biochemically establish the reasons for the differences.

\section{Conclusions}

Our study reveals that at least one other member of the genus Cinnamomum is both attractive to M. rufonota larvae and allows them to complete development. This suggests that it would be worth testing other species that we did not include in the present study. Our findings that three other common Cinnamomum species have very low attractiveness for larvae and are not suitable host plants for their development indicates that these species might be planted in areas where outbreaks of M. rufonota are a problem. It also suggests that these species are unlikely to allow the spread of M. rufonota through areas with a very low density of suitable hosts. The possibility that we might find a species among the five we examined that is attractive to larvae but which they cannot actually utilize as a host-plant was rejected. Our finding that larvae have evolved the capacity to identify suitable hosts using airborne chemical cues and move towards them suggests that it might be possible to develop control methods for $M$. rufonota which utilizes this chemotactic response. Further work to investigate the oviposition preferences of $M$. rufonota adults in relation to potential host plants would provide valuable complementary information to that offered in our study.

Author Contributions: Conceptualization, X.L.; methodology, J.Z. (Jiaying Zhou); software, Q.W.; validation, J.Z. (Jiangtao Zhang), Y.P., and H.S.; formal analysis, J.Z. (Jiangtao Zhang) and Q.W.; investigation, J.Z. (Jiaying Zhou); data curation, J.Z. (Jiaying Zhou), Y.P., and H.S.; writing-original draft preparation, J.Z. (Jiaying Zhou), X.L., and T.T.; writing-review and editing, J.Z. (Jiaying Zhou), X.L., and T.T.; visualization, Q.W.; supervision, X.L.; project administration, X.L.; funding acquisition, X.L. and J.Z. (Jiaying Zhou). All authors have read and agreed to the published version of the manuscript.

Funding: This research was funded in part by the National Natural Science Foundation of China, grant number 31360092, 31760106, the Graduate Innovation Foundation in Jiangxi Province, grant number YC2019-S180, and the project of first-class discipline construction of Forestry in Jiangxi Province.

Acknowledgments: The authors would like to thank editors and two anonymous referees for their helpful comments to improve the manuscript. We thank Paul Hopwood, Tess Cobb (University of Exeter, UK) for help with the statistics and constructive comments on an earlier version of the manuscript.

Conflicts of Interest: The authors declared that they have no conflict of interest.

\section{References}

1. Jaenike, J. Host specialization in phytophagous insects. Annu. Rev. Ecol. Syst. 1990, 21, 243-273. [CrossRef]

2. Schoonhoven, L.M.; van Loon, J.J.A.; Dicke, M. Insect-Plant Biology; Oxford University Press: Oxford, UK, 2005.

3. Thöming, G.; Larsson, M.C.; Hansson, B.S.; Anderson, P. Comparison of plant preference hierarchies of male and female moths and the impact of larval rearing hosts. Ecology 2013, 94, 1744-1752. [CrossRef]

4. Luo, D.; Lai, M.; Xu, C.F.; Shi, H.N.; Liu, X.P. Life history traits in a capital breeding pine caterpillar: Effect of host species and needle age. BMC Ecol. 2018, 18, 24. [CrossRef] 
5. Novotny, V.; Basset, Y.; Miller, S.E.; Drozd, P.; Cizek, L. Host specialization of leaf-chewing insects in a New Guinea rainforest. J. Anim. Ecol. 2002, 71, 400-412. [CrossRef]

6. Jermy, T. Evolution of insect-host plant relationships. Am. Nat. 1984, 124, 609-630. [CrossRef]

7. Gripenberg, S.; Mayhew, P.J.; Parnell, M.; Roslin, T. A meta-analysis of preference-performance relationships in phytophagous insects. Ecol. Lett. 2010, 13, 383-393. [CrossRef]

8. Hafsi, A.; Facon, B.; Ravigné, V.; Chiroleu, F.; Quilici, S.; Chermiti, B.; Duyck, P.F. Host plant range of a fruit fly community (Diptera: Tephritidae): Does fruit composition influence larval performance? BMC Ecol. 2016, 16, 40. [CrossRef] [PubMed]

9. Howe, G.A.; Jander, G. Plant immunity to insect herbivores. Annu. Rev. Plant Biol. 2008, 59, 41-66. [CrossRef] [PubMed]

10. Lee, K.P.; Raubenheimer, D.; Behmer, S.T.; Simpson, S.J. A correlation between macronutrient balancing and insect host-plant range: Evidence from the specialist caterpillar Spodoptera exempta (Walker). J. Insect Physiol. 2003, 49, 1161-1171. [CrossRef]

11. Sylla, S.; Brévault, T.; Monticelli, L.S.; Diarra, K.; Desneux, N. Geographic variation of host preference by the invasive tomato leaf miner Tuta absoluta: Implications for host range expansion. J. Pest Sci. 2019, 92, 1387-1396. [CrossRef]

12. Bernays, E.A.; Chapman, R.F. Host-Plant Selection by Phytophagous Insects; Chapman \& Hall: New York, NY, USA, 1994.

13. Jiao, X.G.; Xie, W.; Wang, S.L.; Wu, Q.J.; Zhou, L.; Pan, H.P.; Liu, B.M.; Zhang, Y.J. Host preference and nymph performance of B and Q putative species of Bemisia tabaci on three host plants. J. Pest Sci. 2012, 85, 423-430. [CrossRef]

14. Ahmad, S. Herbivorous Insects: Host-Seeking Behavior and Mechanisms; Academic Press: New York, NY, USA, 1983.

15. Bruce, T.J.; Wadhams, L.J.; Woodcock, C.M. Insect host location: A volatile situation. Trends Plant Sci. 2005, 10, 269-274. [CrossRef] [PubMed]

16. West, S.A.; Cunningham, J.P. A general model for host plant selection in phytophagous insects. J. Theor. Biol. 2002, 214, 499-513. [CrossRef]

17. Li, Y.X.; Liu, T.X. Oviposition preference, larval performance and adaptation of Trichoplusia ni on cabbage and cotton. Insect Sci. 2014, 22, 273-282. [CrossRef] [PubMed]

18. Coapio, G.G.; Cruz-López, L.; Guerenstein, P.; Malo, E.A.; Rojas, J.C. Oviposition preference and larval performance and behavior of Trichoplusia ni (Lepidoptera: Noctuidae) on host and nonhost plants. Arthropod Plant Interact. 2017, 12, 267-276. [CrossRef]

19. Zalucki, M.P.; Clarke, A.R.; Malcolm, S.B. Ecology and behavior of first instar larval Lepidoptera. Ann. Rev. Entomol. 2002, 47, 361-393. [CrossRef] [PubMed]

20. Soler, R.; Pineda, A.; Li, Y.; Ponzio, C.; van Loon, J.J.A.; Weldegergis, B.T.; Dicke, M. Neonates know better than their mothers when selecting a host plant. Oikos 2012,121, 1923-1934. [CrossRef]

21. Rosenwald, L.C.; Lill, J.T.; Lind, E.M.; Weiss, M.R. Dynamics of host plant selection and host-switching by silver spotted skipper caterpillars. Arthropod Plant Interact. 2017, 11, 833-842. [CrossRef]

22. McCormick, A.C.; Arrigo, L.; Eggenberger, H.; Mescher, M.C.; De Moraes, C.M. Divergent behavioural responses of gypsy moth (Lymantria dispar) caterpillars from three different subspecies to potential host trees. Sci. Rep. 2019, 9, 8953. [CrossRef]

23. Prasad, K.N.; Yang, B.; Dong, X.H.; Jiang, G.X.; Zhang, H.Y.; Xie, H.H.; Jiang, Y.M. Flavonoid contents and antioxidant activities from Cinnamomum species. Innov. Food Sci. Emerg. Technol. 2009, 4, 627-632. [CrossRef]

24. Guo, S.S.; Geng, Z.F.; Zhang, W.J.; Liang, J.Y.; Wang, C.F.; Deng, Z.W.; Du, S.S. The chemical composition of essential oils from Cinnamomum camphora and their insecticidal activity against the stored product pests. Int. J. Mol. Sci. 2016, 17, 1836. [CrossRef] [PubMed]

25. Yan, J.J. Study on the camphor sawfly Mesonurae rufonota (Rohwer). Sci. Silv. Sin. 1962, 8, 184-186, (In Chinese with English summary).

26. Wu, J.F. Biology and control of the Mesoneura rufonota (Rohwer). Acta. Entomol. Sin. 1982, 25, 42-48, (In Chinese with English summary).

27. Chang, K.P.; Hsiau, L.J.; Hsiau, W.F. The studies on the morphology and life cycle of camphor tree leaf bee (Mesonurae rufonota (Rohwer)). Plant Prot. Bull. 1998, 40, 287-295. 
28. Xu, C.F.; Luo, D.; Yin, L.X.; Liu, X.P. Influence of temperature on the development and reproduction of the camphor sawfly, Mesoneura rufonota (Hymenoptera: Tenthredinidae). Acta. Entomol. Sin. 2017, 60, 1216-1225, (In Chinese with English summary).

29. Singer, M.C. The definition and measurement of oviposition preference in plant-feeding insects. In Insect-Plant Interactions; Miller, T.A., Miller, J., Eds.; Springer: New York, NY, USA, 1986; pp. 65-94.

30. Thompson, J.N. Evolutionary ecology of the relationship between oviposition preference and performance of offspring in phytophagous insects. Entomol. Exp. Appl. 1988, 47, 3-14. [CrossRef]

31. Rajapakse, C.N.K.; Walter, G.H. Polyphagy and primary host plants: Oviposition preference versus larval performance in the lepidopteran pest Helicoverpa armigera. Arthropod Plant Interact. 2007, 1, 17-26. [CrossRef]

32. Shikano, I.; Akhtar, Y.; Isman, M.B. Relationship between adult and larval host plant selection and larval performance in the generalist moth, Trichoplusia ni. Arthropod Plant Interact. 2010, 4, 197-205. [CrossRef]

33. Midega, C.A.O.; Khan, Z.R.; Pickett, J.A. Host plant selection behaviour of Chilo partellus and its implication for effectiveness of a trap crop. Entomol. Exp. Appl. 2011, 138, 40-47. [CrossRef]

34. Dethier, V.G. Evolution of feeding preferences in phytophagous insects. Evolution 1954, 8, 33-54. [CrossRef]

35. Rostás, M.; Eggert, K. Ontogenetic and spatio-temporal patterns of induced volatiles in glycine max in the light of the optimal defense hypothesis. Chemoecology 2008, 18, 29-38. [CrossRef]

36. Cao, Y.; Zhi, J.; Cong, C.; Margolies, D.C. Olfactory cues used in host selection by Frankliniella occidentalis (Thysanoptera: Thripidae) in relation to host suitability. J. Insect Behav. 2013, 27, 41-56. [CrossRef]

37. Yang, J.; Sadof, C.S. Variegation in Coleus blumei and the life history of citrus mealybug (Homoptera: Pseudococcidae). Environ. Entomol. 1995, 24, 1650-1655. [CrossRef]

38. Tanga, C.M.; Ekesi, S.; Govender, P.; Mohamed, S.A. Effect of six host plant species on the life history and population growth parameters of Rastrococcus iceryoides (Hemiptera: Pseudococcidae). Fla. Entomol. 2013, 96, 1030-1041. [CrossRef]

39. Altesor, P.; González, A. Preference-performance in a specialist sawfly on congeneric host plants. Entomol. Exp. Appl. 2018, 166, 442-451. [CrossRef]

40. Nethononda, P.D.; Nofemela, R.S.; Modise, D.M. Development, survival, body weight and oviposition rates of Plutella xylostella (Linnaeus) (Lepidoptera: Plutellidae) when reared on seven cabbage cultivars. Afr. Entomol. 2016, 24, 162-169. [CrossRef]

41. Awmack, C.S.; Leather, S.R. Host plant quality and fecundity in herbivorous insects. Annu. Rev. Entomol. 2002, 47, 817-844. [CrossRef]

42. Saeed, R.; Sayyed, A.H.; Shad, S.A.; Zaka, S.M. Effect of different host plants on the fitness of diamond-back moth, Plutella xylostella (Lepidoptera: Plutellidae). Crop Prot. 2010, 29, 178-182. [CrossRef]

43. Strand, M.R.; Casas, J. Parasitoid and host nutritional physiology in behavioural ecology. In Parasitoid Behavioral Ecology; Wajnberg, E., van Alphen, J., Bernstein, C., Eds.; Blackwell Press: Oxford, UK, 2007; pp. 113-128.

44. Winkler, K.; Wäckers, F.L.; Kaufman, L.V.; Larraz, V.; van Lenteren, J.C. Nectar exploitation by herbivores and their parasitoids is a function of flower species and relative humidity. Biol. Control. 2009, 50, 299-306. [CrossRef]

45. Nestel, D.; Papadopoulos, N.T.; Pascacio-Villafán, C.; Righini, N.; Altuzar-Molina, A.R.; Aluja, M. Resource allocation and compensation during development in holometabolous insects. J. Insect Physiol. 2016, 95, 78-88. [CrossRef]

46. Dostálek, T.; Rokaya, M.B.; Maršík, P.; Rezek, J.; Skuhrovec, J.; Pavela, R.; Münzbergová, Z. Trade-off among different anti-herbivore defence strategies along an altitudinal gradient. AoB Plants 2016, 8, plw026. [CrossRef] [PubMed]

47. Maag, D.; Erb, M.; Köllner, T.G.; Gershenzon, J. Defensive weapons and defense signals in plants: Some metabolites serve both roles. BioEssays 2015, 37, 167-174. [CrossRef] [PubMed]

48. Züst, T.; Agrawal, A.A. Trade-offs between plant growth and defense against insect herbivory: An emerging mechanistic synthesis. Annu. Rev. Plant Biol. 2017, 68, 513-534. [CrossRef]

49. Harris, M.O.; Miller, J.R. Host-acceptance behavior in an herbivorous fly, Delia antiqua. J. Insect Physiol. 1988, 34, 179-190. [CrossRef]

(C) 2020 by the authors. Licensee MDPI, Basel, Switzerland. This article is an open access article distributed under the terms and conditions of the Creative Commons Attribution (CC BY) license (http://creativecommons.org/licenses/by/4.0/). 